\title{
Social determinants in child health: reflections from the Health Behaviour in School-aged Children survey
}

\author{
Veronika Ottova • Ulrike Ravens-Sieberer
}

Published online: 3 November 2010

(c) Swiss School of Public Health 2010

Social determinants in child health according to WHO play a major role in Child Public Health (WHO 2003). This is one of the reasons why the International Journal of Public Health has taken up this issue and recently published a supplement titled "Social determinants of child and adolescent health: Findings from the International Health Behaviour in School-aged Children (HBSC) Study". Based on data from the international "Health Behaviour in School-aged Children (HBSC)" Survey, this supplement not only covers key issues on child and adolescent health from a global perspective, but also gives implications for where Child Public Health should be heading in the future.

The importance of social determinants for Public Health arises from the fact that only a fraction of health differences are accounted for by genetics. In fact, "many of the differences are externally determined, such as those related to socioeconomic status" (Barnekow and Muijen 2009, S128). This is confirmed by the HBSC study findings as demonstrated by Ravens-Sieberer et al. (2009) and Holstein et al. (2009) who show that children and adolescents who grow up in disadvantaged conditions not only have a greater risk for fewer protective factors and higher risk factors, but also are at an increased risk for poor subjective health, as well as for psychosomatic complaints. At the same time, HBSC data draw attention to yet another important issue: gender. While gender differences are diminishing on certain health behaviours, e.g. alcohol use (Simons-Morton et al. 2009), elsewhere substantial (and growing) gender gaps are emerging, e.g. subjective health

\footnotetext{
V. Ottova · U. Ravens-Sieberer $(\bowtie)$

Research Unit Child Public Health,

University Medical Center Hamburg-Eppendorf,

Martinistr. 52, W29, 20246 Hamburg, Germany

e-mail: Ravens-Sieberer@uke.uni-hamburg.de
}

(Ravens-Sieberer et al. 2009). Moreover, mental health problems are also emerging as Erhart et al. (2009) point out. Not only older pupils, girls, pupils with low socioeconomic status but also those suffering from frequent health complaints are at greater risk for decreased mental health. The message of these papers is clear: "Mental and physical health, health behaviours, relation with parents and peers are all of a piece" (Marmot 2009, S126).

This trend on rising mental health problems has long been recognized by the World Health Organisation (WHO 2001), which has resulted in various policy commitments, including the Mental Health Action Plan for Europe; the EU Green Paper Improving the mental health of the population: towards a strategy on mental health for the European Union; and the WHO European strategy for child and adolescent health and development. While all these are an important first step in implementing change, the second step, namely an adequate translation of policy into action, is even more crucial. The essence of studies such as the HBSC lies in the fact that "robust data on child and adolescent health status and patterns are essential to develop effective policies and strategies" (Barnekow and Muijen 2009, S130).

The key to successful translation of research into policy and further into practice is that measures and programs account for the social influences on health, including the social structures, people's social positions as well as their access to resources, as highlighted in models on social determinants (Graham 2007). While public health seeks interventions and ways to reduce poor health outcomes and increase positive health, "the HBSC work provides much background evidence on where these changes need to take place, the context and the settings" (McQueen 2009, S124). Too many programs designed to prevent ill health and to promote positive health and well-being are solely 
focused on behaviour change, and fall short of focusing more on the contextual circumstances and environmental conditions which shape and influence children's development. Moreover, they zero in on risk factors, rather than focus their attention on the existing resources in the individual, within the community, etc. - although research has pointed out that investments in strengthening resources, by accumulation of protective factors or assets, especially during adolescence, can help these individuals cope with adverse situations later in life (Morgan and Ziglio 2010).

In this regard, the HBSC survey not only provides robust data on health and health behaviour in an international sample of children and adolescents, but it also delivers researchers, practitioners and policy makers the knowledge necessary for the evaluation and further development of public health policy and practice at different levels (national, sub-national and international). Data with information on social and behavioural issues, as well as gender, geographic and socioeconomic inequalities in health, such as HBSC, can supplement other existing data on morbidity and mortality (Barnekow and Muijen 2009).

As Michael Marmot states: "By themselves these papers do not tell us what should happen next. They are, however, an important part of understanding, which surely must be the basis for informed debate about what should happen next" (Marmot 2009, S126). One of the ways, how the evidence collected in HBSC can be translated into practice and policy making, and how HBSC data can promote health and well-being in children and adolescents and enable a greater understanding of determinants, in particular the social context of young people, is exemplified by the WHO/HBSC Forum process. Initiated in 2006, the WHO/HBSC Forum provides an opportunity for joint work with policy makers, ensuring a better use of HBSC data in policy-making and practice, and hence, effective action on social determinants of health (Koller et al. 2009).

The promotion of health and well-being of children and adolescents remains a challenge. Limited resources, time consuming involvement of communities, deficiency-orientated policies and programs are some of the hindering factors in this process. Nonetheless, and despite these difficulties, it is important to stay committed to the task. Now is the time to reflect upon what research findings are telling us and act upon them. Asset-based interventions seem to be a promising approach to this.

\section{References}

Barnekow V, Muijen M (2009) Child and adolescent health and development in European perspective. Int J Public Health 54:S128-S130

Erhart M, Ottova V, Gaspar T, Jericek H, Schnohr C, Alikasifoglu M, Morgan A, Ravens-Sieberer U, The HBSC Positive Health Focus Group (2009) Measuring mental health and well-being of schoolchildren in 15 European countries using the KIDSCREEN-10 Index. Int J Public Health 54:S160-S166

Graham H (2007) Unequal lives. Health and socioeconomic inequalities. Open University Press, Maidenhead

Holstein BE, Currie C, Boyce W, Damsgaard MT, Gobina I, Kökönyei G, Hetland J, de Looze M, Richter M, Due P, The HBSC Social Inequalities Focus Group (2009) Socio-economic inequality in multiple health complaints among adolescents: international comparative study in 37 countries. Int $\mathrm{J}$ Public Health 54:260-270

Koller T, Morgan A, Guerreiro A, Currie C, Ziglio E, The International HBSC Study Group (2009) Addressing the socioeconomic determinants of adolescent health: experiences from the WHO/HBSC Forum 2007. Int J Public Health 54:S278-S284

Marmot M (2009) Social determinants and adolescent health. Int J Public Health 54:S125-S127

McQueen D (2009) 25 years of HBSC: challenges and successes. Int J Public Health 54:S123-S124

Morgan A, Ziglio E (2010) Revitalising the public health evidence base: an asset model. In: Morgan A, Davies M, Ziglio E (eds) Health assets in a global context, theory, methods, action. Springer, New York

Ravens-Sieberer U, Torsheim T, Hetland J, Vollebergh W, Cavallo F, Jericek H, Alikasifoglu M, Välimaa R, Ottova V, Erhart M, The HBSC Positive Health Focus Group (2009) Subjective health, symptom load and quality of life of children and adolescents in Europe. Int J Public Health 54:S151-S159

Simons-Morton BG, Farhat T, ter Bogt TFM, Hublet A, Kuntsche E, Nic Gabhainn S, Godeau E, Kokkevi A, The HBSC Risk Behaviour Focus Group (2009) Gender specific trends in alcohol use: cross-cultural comparisons from 1998 to 2006 in 24 countries and regions. Int J Public Health 54:S199-S208

World Health Organisation (WHO) (2001) The World Health Report. Mental health: new understanding, new hope. Geneva, Switzerland. http://www.who.int/whr/2001/en/whr01_en.pdf (accessed October 19, 2010)

World Health Organisation (WHO) (2003) The solid facts. Copenhagen, Denmark 